\title{
İkinci Ürün Silajık Mısırda Dinamik Sulama Programının Verim ve Morfolojik Özellikler Üzerine Etkisi
}

\section{Özen KOBAK ${ }^{1}$ (D) ismail TAŞ ${ }^{* 2}$}

\author{
${ }^{1}$ Çanakkale Gıda Kontrol Laboratuvar Müdürlüğü, Çanakkale \\ ${ }^{2}$ Çanakkale Onsekiz Mart Üniversitesi, Ziraat Fakültesi, Tarımsal Yapılar ve Sulama Bölümü, Terzioglu \\ Yerleskesi, Çanakkale
}

Öz: Bu çalışma, dinamik sulama programıyla sulanan II. Ürün silajlık mısırın (Zea mays) verim ve morfolojik özelliklerine etkisini belirlemek amacıyla Balıkesir ili Manyas ilçesi ekolojik koşullarında 2016 yılında yürütülmüştür. Dinamik sulama programının oluşturulmasında FAO Penman Monteith yönteminden yararlanılmıştır. Günlük iklim verilerinden hesaplanan evapotranspirasyon (ETo) değerleri bitki katsayıları $(\mathrm{KC})$ ile düzeltilerek uygulanmıştır. Çalışma tesadüf blokları bölünmüş parseller deneme deseninde 3 tekrarlı olarak yürütülmüştür. Çalışmada 3 farklı sulama aralığı $(3,6$ ve 9 gün) ve 3 evapotranspirasyon (ETc) seviyesi (\%75, \%100 ve \%125) incelenmiştir. Araştırma sonucunda; mısır bitkisinin mevsimlik gerçek evapotranspirasyonu (ETa) 320-582 mm, Su Kullanım Randımanı (WUE) 3.91-5.82 kg/da/mm, Sulama Suyu Kullanım Randımanı (IWUE) 4.26-6.92 kg/da/mm, yeşil ot verimi $6087.78-11062.82 \mathrm{~kg} / \mathrm{da}$, bitki boyu $222.8-283 \mathrm{~cm}$, yaprak sayısı 10.33-13.33 adet, yaprak ağırlığı 114.56-256.18 gr, sap çapı 17.2-27.3 mm, sap ağılığı 544-710 gr, ilk koçan yüksekliği 71.66101.16 cm, koçan ağırlığı 342-594 gr ve bitki ağırlığı 1193-1502 gr arasında değişiklik göstermiştir. En yüksek bitki boyu üç günlük sulama aralığında hesaplanan yığışımlı ETc değerinin \%125'nin uygulandığı konuda $(274 \mathrm{~cm})$ alınırken, en yüksek yeşil ot verimi ise altı günlük sulama aralığında hesaplanan yığışımlı ETc değerinin \%75'nin uygulandığı konudan (11062 kg/da) elde edilmiştir.

\section{Anahtar Kelimeler: FAO Penman Monteith, Damla Sulama, ETo, ETc, ETa}

\section{The Effect of Dynamic Irrigation Scheduling on Yield and Morphological Properties of Second Crop Silage Corn}

\begin{abstract}
The aim of this study was to determine the effect of dynamic irrigation program on the yield and morphological characteristics of second crop silage maize (Zea mays) in 2016 under the ecological conditions of Manyas district of Balıkesir province. The FAO Penman Monteith method was used to create the dynamic irrigation program. Evapotranspiration (ETo) values calculated from daily climate data were applied by correcting them with plant coefficients (Kc). The study was carried out in randomized blocks divided plots test design in 3 replicates. In the study, 3 different irrigation intervals (3, 6 and 9 days) and 3 evapotranspiration (Etc) levels (75\%, 100\% and 125\%) were examined. As a result of the research; maize seasonal actual evapotranspiration (ETa) 320-582 mm, Water Use Efficiency (WUE) 3.91-5.82 $\mathrm{kg} / \mathrm{da} / \mathrm{mm}$, Irrigation Water Use Efficiency (IWUE) 4.26-6.92 kg/da/mm, green grass yield 6087.78-11062.82 kg/da, plant height 222.8-283 $\mathrm{cm}$, leaf number 10.33-13.33, leaf weight $114.56-256.18 \mathrm{~g}$, stem diameter 17.2-27.3 mm, stem weight 544-710 g, first cob height 71.66$101.16 \mathrm{~cm}$, cob weight 342 -594 gr and plant weight varied between 1193-1502 gr. The highest plant height (274 cm) was taken in the area where $125 \%$ of the cumulative ETc value calculated in the three day irrigation interval is applied, while the highest green grass yield (11062 $\mathrm{kg} / \mathrm{da}$ ) was from the subject where $75 \%$ of the cumulative ETc value calculated in the six day irrigation interval has been obtained.
\end{abstract}

Keywords: FAO Penman Monteith, Drip Irrigation, ETo, ETC, ETa

GiRiş

Tarımda kullanılan sulama suyu, su kaynaklarının yaklaşık \%70'ten fazlasını oluşturmaktadır. Ülkemizde de büyük bir problem olan kuraklık, yerüstü ve yeraltı kaynaklarını olumsuz anlamda etkilemektedir. Kentsel ve endüstriyel kullanımdaki gereksinimler, su kaynaklarının kullanımı açısından sektörler arasında önemli derecede rekabet oluşturmaktadır. Basınçlı sulama sistemlerinden olan damla sulama yöntemi, su kaynaklarını etkin bir şekilde kullanılmasına olanak sağlamaktadır. Bu yöntemle suyun, derine sızmasının önlenmesi, yüzey akışının önlenmesi ve buharlaşmanın minimuma indirilmesi gibi ciddi bir su tasarrufu sağlanmaktadır. Önceki yıllarda damla sulama yöntemi daha çok meyve bahçeleri ve seralarda kullanılmasına karşın, artık günümüzde mısır, pamuk ve çoğu sebze gibi sıra bitkilerinde de kullanımı oldukça yaygındır. Su kaynaklarının optimum kullanılmasında, su tasarrufu sağlayan damla sulama yöntemi tercih edilmektedir. Modern sulama teknolojilerinin kullanılması, uygun gübre kullanımı ve sulama programları ile verimde de ciddi artışlar sağlamaktadır. Su uygulama randımanı damla sulama yöntemlerinde \%95'e kadar çıkmaktadır. Bununla birlikte bitkilerin su kullanım etkinliği de artmaktadır (Bozkurt, 2005).

Mısır, insan ve hayvan beslenmesinde ve endüstri hammaddesi olarak çok geniş bir kullanım alanına sahiptir. Mısır bitkisi bir sıcak iklim tahılı olması nedeni ile güneş

*Sorumlu Yazar: tas ismail@yahoo.com. Bu çalışma yüksek lisans tez ürünüdür.

Geliş Tarihi: 16 Eylül 2020

Kabul Tarihi: 28 Aralık 2020 
enerjisini de çok iyi kullanır ve aynı zamanda birim alanda çok fazla kuru madde üreten bir bitkidir (Kırtok, 1998). Mısırın, çevre koşullarına iyi adapte olabilmesi, çeşit zenginliği olması ve yüksek verim potansiyeli olmasıyla yayılma alanı çok geniştir (Yasak ve ark., 2003). Silaj, hayvanların kaba yem ihtiyaçlarının karşılanmasında önemli bir yere sahiptir. Süt üretimi için kullanılan ineklerin tükettikleri yemlerin en az \%40 oranına yakını kaba yemlerden sağlanmalıdır. Hayvancılıkla uğraşan çiftçiler kaba yem bulmakta güçlük çektikleri zaman, hayvanları saman ile beslemektedirler. Günümüzde çiftçiler, hayvanları besin ve karbonhidrat içeriği daha yüksek suca zengin olan silajı tercih etmeye başlamışlardır (Orak ve İptaş, 1999). Silaj üretimine uygun birçok yem bitkisi ülkemizin çoğu yerinde yetiştirilmektedir. En fazla sorgum tür ve melezleri ile mısır, silo yemi üretilmesinde kullanılmaktadır (Sağlamtimur ve ark., 1998). Ayrıca mısır, hayvanlar tarafından kolayca sindirilen ve birim alandan yüksek verim alınan bir tahıldır (Açıkgöz, 1995). Silaj, hayvanların kışıı kaba yem ihtiyaçlarına büyük oranda katkı sağladığı için yaygın olarak kullanılmaktadır (Yolcu ve Tan, 2008).

Arıtürk (2008), Tekirdağ bölgesinde ikinci ürün mısırda farklı sulama metotları, (damla sulama ve karık sulama) tam ve kısıtlı sulama uygulamaları altında sulama programı oluşturmak amacıyla yürütülen çalışmada, mevsimlik bitki su tüketimi değerleri karık sulamada 388-506 mm, damla sulamada 293-429 mm arasında değişiklik gösterdiği elde edilmiştir. En yüksek yeşil ot verimi karık sulama için 9896 $\mathrm{kg} / \mathrm{da}$ ve damla sulama için $9291 \mathrm{~kg} / \mathrm{da}$ sulama süresince sulama suyunun tam olarak verildiği dönemde elde edilmiştir. Sulama suyu kullanım randımanı değerlerinin karık sulamada $20.83-27.00 \mathrm{~kg} / \mathrm{da} / \mathrm{mm}$ ve damla sulamada 19.56-21.92 kg/da/mm arasında değişiklik göstermiştir. Su kullanım randımanları değerlerinin ise karık sulamada 21.92-23.67 kg/da/mm ve damla sulamada 21.66-29.52 $\mathrm{kg} / \mathrm{da} / \mathrm{mm}$ arasında değişiklik gösterdiği bildirilmiştir. Sonuç olarak farklı sulama yöntemlerinde verim ve verim elamanları istatistiksel açıdan önemsiz olurken, sulama düzeyleri arasındaki fark istatistiksel açıdan önemli olduğu çalışmada belirtilmiştir.

Bilindiği gibi sulama zamanı planlamalarında farklı yöntemler ve araçlar kullanılmaktadır. Kullanılan yöntemlerden bir tanesi de dinamik sulama programlamasıdır. Söz konusu yöntemin temeli, arazide bulunana iklim istasyonundan ölçülen günlük iklim parametrelerinden yararlanarak istenilen bir yöntemle ETo değerlerinin hesaplanmasına dayanır. Hesaplanan ETo değerleri bitki katsayısı ile düzeltilerek (düzeltme işleminden sonra ETc simgesi ile gösterilmiştir) sulamada kullanılır. Yapılan bu çalışmada da yukarıda belirtildiği gibi belirlenen dinamik sulama programının, Balıkesir-Manyas koşullarında ikinci ürün silajlık mısırın verim ve morfolojik özellikleri üzerine olan etkisi incelenmiştir.

\section{MATERYAL VE YÖNTEM}

\section{Materyal}

Bu araştırma, Balıkesir ili Manyas ilçesi Çakırca köyü Çay Boyu mevkiinde bulunan bir çiftçi arazisinde gerçekleştirilmiştir. Deneme alanı $40^{\circ} 02^{\prime}$ enlem ve $27^{\circ} 51^{\prime}$ boylamında yer almaktadır. Arazinin rakımı 52 m’dir.

\section{Araştırma Alanının İklim Özellikleri}

Balıkesir ili Manyas ilçesine ait uzun yıllık bazı iklim verileri Balıkesir Meteoroloji ì Müdürlüğünden elde edilmiştir. 1938-2017 yılları arasında yapılan ölçümler neticesinde elde edilen veriler Çizelge 1'de gösterilmiştir. Çizelgeden de belirtildiği üzere, Manyas'ta uzun yıllar gözlemlerine göre maksimum sıcaklık $43.9{ }^{\circ} \mathrm{C}$, minimum sıcaklık $-14.6{ }^{\circ} \mathrm{C}$,

Çizelge 1. Balıkesir ili Manyas ilçesi uzun yıllara ait bazı iklim verileri (1938-2017)

\begin{tabular}{|c|c|c|c|c|c|c|}
\hline \multirow{2}{*}{ Aylar } & \multicolumn{3}{|c|}{ Sıcaklık ( $\left.{ }^{\circ} \mathrm{C}\right)$} & \multirow{2}{*}{$\begin{array}{c}\text { Nispi Nem } \\
\text { (\%) }\end{array}$} & \multirow{2}{*}{$\begin{array}{l}\text { Ort. Rüzgar Hızı } \\
\text { (m/sn) }\end{array}$} & \multirow{2}{*}{$\begin{array}{l}\text { Ort. Yağış Miktarı } \\
\left(\mathrm{mm} / \mathrm{m}^{2}\right)\end{array}$} \\
\hline & Ort. & Mak. & Min. & & & \\
\hline Ocak & 5.6 & 23.6 & -14.6 & 84.1 & 2.7 & 143.7 \\
\hline Şubat & 7.3 & 27 & -10.7 & 82.1 & 2.9 & 99.5 \\
\hline Mart & 9.6 & 27.1 & -4.4 & 77.5 & 2.5 & 14.1 \\
\hline Nisan & 13.1 & 33.6 & -3.2 & 73.5 & 2.2 & 33.3 \\
\hline Mayıs & 18.2 & 35.7 & 1.1 & 70.4 & 2.0 & 17.0 \\
\hline Haziran & 22.7 & 43.9 & 7.6 & 66.6 & 2.0 & 30.2 \\
\hline Temmuz & 24.8 & 41.8 & 11.5 & 64.6 & 2.1 & 1.1 \\
\hline Ağustos & 24.7 & 40.2 & 11.2 & 67.7 & 2.1 & 2.8 \\
\hline Eylül & 20.8 & 40.6 & 6.4 & 70.4 & 1.8 & 0.3 \\
\hline Ekim & 15.5 & 31.9 & 0.7 & 81.8 & 1.8 & 115.4 \\
\hline Kasım & 11 & 29.7 & -3.4 & 83.8 & 1.9 & 129.1 \\
\hline Aralık & 7.1 & 26.7 & -12.1 & 84.7 & 2.1 & 52.9 \\
\hline Yıllık & 15 & 43,9 & $-14,6$ & 75,6 & 2.2 & 639.4 \\
\hline
\end{tabular}


ortalama sıcaklık $15{ }^{\circ} \mathrm{C}$, ortalama nisbi nem \%75.6, ortalama rüzgar hızı $2.2 \mathrm{~m} / \mathrm{s}$ yıllık ortalama yağış toplam 639.4 $\mathrm{mm} / \mathrm{m}^{2}$ dir.

Deneme alanı yakınında bulunan otomatik iklim istasyonundan ölçülen iklim parametrelerinden yararlanılarak dinamik sulama programı planlanmıştır. Bitki su tüketimi hesaplanmasında kullanılan veriler Çizelge 2'de verilmiştir. Üretim sezonu boyunca ölçülen değerler 10'ar günlük periyotlarla söz konusu çizelgede sunulmuştur. Üretim sezonunda ölçülen değerlere göre, en yüksek solar radyasyon Temmuz ayının ilk döneminde $303.78 \mathrm{~W} / \mathrm{m}^{2}$, en düşük $142.15 \mathrm{~W} / \mathrm{m}^{2}$ ile Eylül ayının son döneminde gerçekleştirilmiştir.

Temmuz ayı içerisinde yağış gerçekleşmemiştir. En fazla yağış Eylül ayı 2. döneminde $1.66 \mathrm{~mm}$ olarak gözlemlenmiştir. Rüzgar hızı en yüksek Temmuz ayının 3. döneminde $1.25 \mathrm{~m} / \mathrm{sn}$, en düşük $0.44 \mathrm{~m} / \mathrm{sn}$ ile Eylül ayının 3. döneminde görülmüştür. Hava sıcaklığı en yüksek Ağustos ayının ilk döneminde ortalama $26.81{ }^{\circ} \mathrm{C}$, en düşük
KOBAK Ö, TAŞ $\mathrm{i}$

Eylül ayı 3. döneminde ortalama $15.74{ }^{\circ} \mathrm{C}$ olarak ölçülmüştür. Nispi nem en yüksek Eylül ayının 3. döneminde \%77.84, en düşük \%65.11 ile Temmuz ayının ilk döneminde tespit edilmiştir. FAO Penman-Monteith (1998) referans bitki su tüketimleri (ETo), en yüksek Temmuz ayının ilk döneminde $5.5 \mathrm{~mm}$, en düşük Eylül ayının son döneminde $1.91 \mathrm{~mm}$ olarak hesaplanmıştır.

\section{Deneme Alanının Toprak Özellikleri}

Denemenin yapıldığı alanda herhangi bir taban suyu, tuzluluk ve drenaj yetersizliği gibi olumsuz bir durum tespit edilmemiştir. Deneme parselinde $30 \mathrm{~cm}$ 'lik katmanlar halinde $120 \mathrm{~cm}$ derinliğe kadar örnekleme yapılmış ve analizleri de Çanakkale Tarım Orman iı Müdürlüğü Toprak ve Su Laboratuvarı'nda yapılmıştır. Çizelge 3 'de görüldüğü üzere araştırma alanında topraklar $0-30 \mathrm{~cm}$ derinliğinde tınlı bir bünyeye sahipken derinlere inildikçe killi tınlı bünye yapısına sahiptir. Ortalama kil oranı \%27.37, silt oranı \%36.84, kum oranı ise \%35.79'dur. Ortalama $\mathrm{pH} 7.46$ ve EC $880 \mu \mathrm{mhos} / \mathrm{cm}^{\prime}$ dir. Organik madde içeriği $0-30 \mathrm{~cm}$ toprak Çizelge 2. Deneme alanına ait gelişme sezonunda kaydedilen iklim parametreleri

\begin{tabular}{|c|c|c|c|c|c|c|}
\hline Tarih & $\begin{array}{c}\text { Solar Radyasyon } \\
\left(\mathrm{W} / \mathrm{m}^{2}\right)\end{array}$ & $\begin{array}{l}\text { Yağış } \\
\text { (mm) }\end{array}$ & $\begin{array}{c}\text { Rüzgar Hızı } \\
\text { (m/sn) }\end{array}$ & $\begin{array}{c}\text { Hava } \\
\left.\text { Sıcaklığı ( }{ }^{\circ} \mathrm{C}\right)\end{array}$ & $\begin{array}{c}\text { Nispi Nem } \\
\text { (\%) }\end{array}$ & ETo $(\mathrm{mm})$ \\
\hline 1. Dönem Temmuz & 303.78 & 0.00 & 1.22 & 25.27 & 65.11 & 5.50 \\
\hline 2. Dönem Temmuz & 292.95 & 0.00 & 0.82 & 25.07 & 67.62 & 5.06 \\
\hline 3. Dönem Temmuz & 284.61 & 0.00 & 1.25 & 25.29 & 65.19 & 5.20 \\
\hline 1. Dönem Ağustos & 250.68 & 0.04 & 1.14 & 26.81 & 73.07 & 4.73 \\
\hline 2. Dönem Ağustos & 220.25 & 0.02 & 1.22 & 23.97 & 69.92 & 4.07 \\
\hline 3. Dönem Ağustos & 215.25 & 0.00 & 1.06 & 24.39 & 71.82 & 3.84 \\
\hline 1. Dönem Eylül & 201.04 & 0.00 & 0.95 & 23.44 & 67.98 & 3.55 \\
\hline 2. Dönem Eylül & 173.08 & 1.66 & 0.71 & 22.22 & 65.60 & 2.84 \\
\hline 3. Dönem Eylül & 142.15 & 0.46 & 0.44 & 15.74 & 77.84 & 1.91 \\
\hline
\end{tabular}

Çizelge 3. Toprak örneklerine ait bazı fiziksel ve kimyasal özellikler

\begin{tabular}{|c|c|c|c|c|c|}
\hline Derinlikleri & $0-30$ & $30-60$ & $60-90$ & $90-120$ & Ortalama \\
\hline Kum (\%) & 38.33 & 32.83 & 35.54 & 36.48 & 35.80 \\
\hline Kil (\%) & 22.19 & 29.07 & 27.76 & 30.46 & 27.37 \\
\hline Silt (\%) & 39.49 & 38.1 & 36.71 & 33.07 & 36.84 \\
\hline Bünye & Tınlı & Killi-Tın & Killi-Tın & Killi-Tın & Killi-Tın \\
\hline İşba (\%) & 70 & 65 & 58 & 55 & 62 \\
\hline $\mathrm{pH}$ & 7.35 & 7.59 & 7.52 & 7.39 & 7.46 \\
\hline $\mathrm{EC}(\mathrm{mS} / \mathrm{cm})$ & 0.98 & 0.84 & 0.87 & 0.84 & 0.88 \\
\hline Kireç (\%) & 3 & 3 & 3 & 3 & 3.00 \\
\hline Organik Madde (\%) & 21.23 & 18.99 & 13.12 & 12.99 & 16.58 \\
\hline$P(k g / d a)$ & 0.318 & 0.147 & 0.149 & 0.128 & 0.19 \\
\hline $\mathrm{K}(\mathrm{kg} / \mathrm{da})$ & 68 & 28 & 27 & 24 & 36.75 \\
\hline Tarla Kapasitesi (p/w) & 41.13 & 39.84 & 38.30 & 35.73 & 38.75 \\
\hline Solma Noktası (p/w) & 17 & 17.3 & 19.81 & 19.38 & 18.37 \\
\hline Hacim ağırlığı $\left(\mathrm{gr} / \mathrm{cm}^{3}\right)$ & 1.2 & 1.19 & 1.16 & 1.18 & 1.18 \\
\hline
\end{tabular}


derinliğinde \%21.23 iken toprak derinliğine inildikçe bu oran düşmekte, $90-120 \mathrm{~cm}$ toprak derinliğinde \%12.99'dur. Toprakların organik madde yüksekliğinin nedeni olarak, tarım alanının uzun yıllar çeltik üretiminde kullanılması olarak değerlendirilmiştir.

\section{Bitki Materyali}

Mısır çeşidi olarak da May Tohumculuğun Hido çeşidi kullanılmıştır. Çeşit, FAO 7000 olgunlaşma grubunda bulunmaktadır. Ekolojiye ve bakım şartlarına göre değişim göstermekle birlikte silajlık olarak, 100-110 günlük gelişme gününe sahiptir. Çimlenme ve çıkış gücü de oldukça yüksektir. Yaprak yapısı yarı dik olup, yaprak/koçan oranı yüksektir. Koçan uç doldurması iyi düzeydedir. İdeal koşullar altında silaj halinde ham protein oranı \%9 civarlarında, nişasta oranı \%30 civarındadır. Farklı iklim koşullarına adaptasyonu oldukça yüksektir. Yeşil kalma özelliği, olgunlaşma aşamasında çok yüksektir. Ekim sıklığı $70 \mathrm{~cm}$ sıralar arasındaki mesafe, $13 \mathrm{~cm}$ ise sıralar üzerindeki mesafe olarak tavsiye edilmektedir. Toprak seçiciliği oldukça azdır (Anonim, 2019).

\section{Sulama Suyunun Kalitesi}

Ihtiyaç duyulana sulama suyu, araştırma parselinin yanındaki artezyen kuyusundan sağlanmıştır. Sulama suyu Çanakkale Tarım Orman ì Müdürlüğü Toprak ve Su Laboratuvarı'nda analiz edilmiş ve Çizelge 4'te verilmiştir. Sulama suyu $T_{3} A_{1}$ sınıfında olup Sodyum Adsorbsiyon Oranı (SAR) değeri 0.44 olarak hesaplanmıştır. Elektiriksel iletkenlik değeri $782 \mu \mathrm{mhos} / \mathrm{cm}$ bulunurken pH'sı 7.25 olarak ölçülmüştür. Sulama suyunun mısır yetiştiriciliği açsından her hangi bir sakıncası bulunmamaktadır.

\section{Tarımsal isşlemler}

Ekim sırasında taban gübresi olarak kompoze 15-15-15 gübresi uygulanmıştır. Toplam dekara saf azot olarak $30 \mathrm{~kg}$ olacak şekilde gübreleme yapılmıştır. Taban gübrelemesinden geriye kalan azot miktarı üre formunda üç eşit parçaya bölünerek damla sulama sistemiyle uygulanmıştır. Araştırma boyunca yabancı otlarla mücadele için üç farklı zaman diliminde çapalama yapılmış ve haşere ilaçlaması için ihtiyaç duyulan insektisit uygulamaları yapılmıştır.

\section{Yöntem}

\section{Deneme Deseni ve Araştırma Konuları}

Çalışma tesadüf blokları bölünmüş parseller deneme deseninde 3 tekrarlı olarak Şekil 1'de gösterildiği biçimde oluşturulmuştur. Çalışmada 3 farklı sulama aralığı (3, 6 ve 9 gün) ve hesaplanan ETo değerlerinin $\mathrm{Kc}$ ile düzeltilmiş miktarlarının (ETc) 3 farklı (\%75, \%100 ve \%125) düzeyi uygulanmıştır. Tekerrürler T1, T2 ve T3 ile gösterilmiştir.

Çalışma konuları ise aşağıdaki şekilde oluşturulmuştur.

T3KS75 : 3 günde bir yığışımlı ETc değerinin \%75'nin uygulandığı konu

T3TS100 : 3 günde bir yığışımlı ETc değerinin \%100'nün uygulandığı konu

T3FS125 : 3 günde bir yığışımlı ETc değerinin \%125'nin uygulandığı konu

T6KS75 : 6 günde bir yığışımlı ETc değerinin \%75'nin uygulandığı konu

T6TS100 : 6 günde bir yığışımlı ETc değerinin \%100'nün uygulandığı konu

T6FS125 : 6 günde bir yığışımlı ETc değerinin \%125'nin uygulandığı konu

T9KS75 : 9 günde bir yığışımlı ETc değerinin \%75'nin uygulandığı konu

T9TS100 : 9 günde bir yığışımlı ETc değerinin \%100’nün uygulandığı konu

T9FS125 : 9 günde bir yığışımlı ETc değerinin \%125’nin uygulandığı konu

\section{Sulamaların Planlanması ve Uygulanması}

İlk sulamada araziden alınan toprak örneğinden belirlenen mevcut toprak nemi tarla kapasitesine gelinceye kadar sulama yapılmıştır. Sonraki su yaklaşık 2 hafta sonra uygulanmıştır. Bitki 3-4 yapraklı olunca konulu sulamalara başlanmıştır. FAO Penman Monteith yöntemi ile günlük iklim verilerinden hesaplanan ETo değerleri bitki katsayıları

Çizelge 4. Deneme alanındaki sulama suyuna ait analiz sonuçları

\begin{tabular}{|c|c|c|c|c|c|c|c|c|c|c|c|c|}
\hline \multirow{2}{*}{$\begin{array}{l}\text { EC } \\
\mu \text { mhos/ } \\
\mathrm{cm}\end{array}$} & \multirow{2}{*}{$\mathrm{pH}$} & \multicolumn{4}{|c|}{ Katyonlar(me/l) } & \multicolumn{4}{|c|}{ Anyonlar(me/l) } & \multirow{2}{*}{$\begin{array}{l}\mathrm{Na} \\
\text { (\%) }\end{array}$} & \multirow{2}{*}{ SAR } & \multirow{2}{*}{ Sinıf } \\
\hline & & $\mathrm{Na}$ & K & $\mathrm{Ca}$ & $\mathrm{Mg}$ & $\mathrm{CO}_{3}$ & $\mathrm{HO}_{3}$ & $\mathrm{Cl}$ & $\mathrm{SO}_{4}$ & & & \\
\hline 782 & 7.25 & 0.94 & 0.06 & 5.8 & 3.1 & - & 2.8 & 1.5 & 5.6 & 0.09 & 0.44 & $\mathrm{~T}_{3} \mathrm{~A}_{1}$ \\
\hline
\end{tabular}

\begin{tabular}{|c|c|c|c|c|c|c|c|c|}
\hline \multicolumn{3}{|c|}{ Sulama Aralığı 3 gün } & \multicolumn{3}{c|}{ Sulama Aralığı 6 gün } & \multicolumn{3}{c|}{ Sulama Aralığı 9 gün } \\
\hline T3KS75 T1 & T3TS100 T1 & T3FS125 T1 & T6KS75 T1 & T6TS100 T1 & T6FS125 T1 & T9KS75 T1 & T9TS100 T1 & T9FS125 T1 \\
\hline T3KS75 T2 & T3TS100 T2 & T3FS125 T2 & T6KS75 T2 & T6TS100 T2 & T6FS125 T2 & T9KS75 T2 & T9TS100 T2 & T9FS125 T2 \\
\hline T3KS75 T3 & T3TS100 T3 & T3FS125 T3 & T6KS75 T3 & T6TS100 T3 & T6FS125 T3 & T9KS75 T9 & T9TS100 T9 & T9FS125 T9 \\
\hline
\end{tabular}

Şekil 1. Deneme Planı 
(Kc) ile düzeltilmiş ve sulama uygulamasında kullanılmıştır. Sulama planlamasında yığışımlı evapotranspirasyon değerleri 3, 6 ve 9 günlük sulama aralıklarında 3 farklı (\%75, \%100 ve \%125) düzeyde olacak şekilde uygulanmıştır. Kc değerleri "Türkiye'de Sulanan Bitkilerin Bitki Su Tüketimleri" rehberinden Manyas'a ilişkin değerlerin bulunmaması nedeniyle en yakın istasyon olarak Gönen belirlenmiş ve söz konusu istasyonuna ilişkin değerler alınmıştır. Hesaplamalarda kullanılan Kc değerleri dönemlerine göre sırasıyla 1. dönem: 0.23, 3. dönem: 1.21 ve 4. dönem: 0.52 'dir.

\section{Bitki Su Tüketimi}

Dinamik sulama programının oluşturulmasında FAO Penman Monteith yönteminden yararlanılmıştır. FAO tarafından 1990 yılında birçok uzman bir araya getirilerek Penman Monteith yöntemi geliştirilmiş ve FAO Penman Monteith yöntemi geliştirlmiştir. Farklı ülkeler arasında farklı adlandırılan bu yöntem, potansiyel su tüketimi yerine referans bitki su tüketimi kavramı ile FA056-PM olarak kabul edilemeye başlanmıştır (Allen ve ark., 1998). Bu yöntemde referans bitki su tüketimi aşağıdaki eşitlikle hesaplanmaktadır.

ETo $=\frac{0.408 \Delta\left(R_{n}-\mathrm{G}\right)+\gamma \frac{900}{T+273} U_{2}\left(e_{s}-e_{a}\right)}{\Delta+\gamma\left(1+0.34 U_{2}\right)}$

Eşitlikte;

ETo = Referans evapotranspirasyon ( $\mathrm{mm} /$ gün),

$\mathrm{Rn}=$ Bitki yüzeyindeki net radyasyon $\left(\mathrm{MJ} / \mathrm{m}^{2}\right.$ gün),

$\mathrm{G}=$ Zemin ısı değişim yoğunluğu ( $\mathrm{MJ} / \mathrm{m} 2$ gün),

$\mathrm{T}=2 \mathrm{~m}$ yükseklikteki ortalama günlük hava sıcaklığı $\left({ }^{\circ} \mathrm{C}\right)$,

$\mathrm{u}_{2}=2 \mathrm{~m}$ yükseklikteki rüzgâr hızı $(\mathrm{m} / \mathrm{s})$,

$\mathrm{e}_{\mathrm{s}}=$ Doygun buhar basıncı $(k P a)$,

$\mathrm{e}_{\mathrm{a}}=$ Gerçek buhar basıncı $(\mathrm{kPa})$,

$\mathrm{e}_{\mathrm{s}}-\mathrm{e}_{\mathrm{a}}=$ Havanın doygun buhar basıncı açığı $(\mathrm{kPa})$,

$\Delta=$ buhar basıncı eğrisi eğim $\mathrm{kPa} /{ }^{\circ} \mathrm{C}$ ),

$\mathrm{V}=$ Psikrometrik sabit $\left(\mathrm{kPa} /{ }^{\circ} \mathrm{C}\right)$.

FAO Penman Monteith yöntemi ile günlük iklim verilerinden hesaplanan ETo değerleri bitki katsayıları (Kc) ile düzeltilerek mısır bitkisi için ETc (ETc=ETo $x \mathrm{Kc}$ ) değeri olarak hesaplanmış ve sulama suyu miktarının belirlenmesinde kullanılmıştır.

\section{Su Kullanım Randımanı}

Su kullanım randımanları (WUE), sulama programlarının değerlendirilmesinde ve sulama yöntemlerinin karşılaştırılmasında kullanılan ifadelerden birisidir (Tanner ve Sinclair, 1983). Parametrelerin hesaplanmasında Howell ve ark., (1990)'ın verdiği eşitlik kullanılmıştır.

$W U E=\frac{E y}{E T} * 100$

WUE: Su kullanım randımanı

Ey: Verim, $(\mathrm{kg} / \mathrm{da})$

ET: Bitki su tüketimi, ( $\mathrm{mm})$
KOBAK Ö, TAŞ i Sulama suyu uygulama randımanı (IWUE) tespit edilmesindeyse aşağıda verilen eşitlik kullanılmıştır (Kanber ve ark., 1992).

$I W U E=\frac{E y}{I} * 100$

IWUE: Sulama suyu kullanım etkinliği

Ey: Ekonomik verim, (kg/da)

I: Sulama suyu, (mm)

\section{Toprak Su İçeriği}

Her bir konudan tüm sulama günlerinin aynı güne geldiği zaman dilimde ve sulama öncesinde her konudan belirlenen yerlerde $0-30 \mathrm{~cm}, 30-60 \mathrm{~cm}, 60-90 \mathrm{~cm}, 90-120 \mathrm{~cm}$ katmanlarından toprak burgusu ile alınan toprak örneklerine ait gravimetrik toprak nem içeriği, etüvde 105 ${ }^{\circ} C^{\prime}$ de 24 saatte su içerikleri uçurularak Eşitlik 4 yardımıyla belirlenmiştir.

$\%$ Nem $=\frac{\text { Yaş Ağırlık-Kuru Ağırlık }}{\text { Kuru Ağırlık }} * 100$

\section{Denemede İncelenen Morfolojik Özellikler}

Yeşil Ot Verimi: Koçan püskülünün kurumasıyla, tamamlanan süt-hamur olum dönümü sonrasında destek köklerin üzerindeki ilk boğum noktasından kesilmek suretiyle hasat gerçekleştirilmiş ve toplamdaki yaş ağırlıklar tartılarak verim alan üzerinden $\mathrm{kg} / \mathrm{da}$ olarak hesaplanmıştır. Bitki Boyu: Her bir konudan tesadüfi olarak belirlenen yerlerden alınan 5 farklı bitkide, toprağın yüzeyindeki kısımdan başlayarak, tepe püskülünün ucuna kadar olan mesafe arasında kalan kısmı şeritmetre ile $\mathrm{cm}$ biriminde ölçülmüştür.

Yaprak Sayısı: Her bir konudan tesadüf şeklinde belirlenen yerlerden alınan 5 farklı bitkinin üzerindeki tüm yaprakları sayılarak ölçülmüştür.

Yaprak Ağırlığı: Her bir konudan tesadüfi olarak belirlenen yerlerden alınan 5 farklı bitkinin yaprakları ayrılıp tartılarak bulunmuştur.

Bitki Sap Çapı: Her bir konudan tesadüfi olarak belirlenen yerlerden alınan 5 farklı bitkinin, koçan altındaki yerde oluşan ilk boğumdan bir kumpas yardımıyla sap kalınlıkları ölçülür ve $\mathrm{mm}$ olarak belirlenir.

Bitki Sap Ağırlığı: Her bir konudan tesadüfi olarak belirlenen yerlerden alınan 5 farklı bitkinin koçanları ve yaprakları ayrılıp sadece sapları tartılarak hesaplanmıştır.

IIk Koçan Yüksekliği: Her bir konudan tesadüfi olarak belirlenen yerlerden alınan 5 farklı bitkinin toprak yüzeyi ve ilk koçanların bağlandığı boğum arasında kalan mesafe, dikey şekilde $\mathrm{cm}$ olarak ölçülmüştür.

Koçan Ağırlığı: Her bir konudan tesadüfi olarak belirlenen yerlerden alınan 5 farklı bitkinin koçanları ayrılarak tartılıp ölçülmüştür.

Bitki Ağırlığı: Her bir konudan tesadüfi olarak belirlenen yerlerden alınan 5 farklı bitkinin $5 \mathrm{~cm}$ yüksekliğinden kesilerek, yeşil olarak yaprak sap ve koçanlarının ayrı ayrı 
tartılarak ortalamaları alınıp hesaplanmıştır (İptaş ve Avcıoğlu, 1997).

\section{İstatistiksel Değerlendirme}

Çalışmadan elde edilen değerler JMP istatistik programında analiz edilmiş ve değerlendirilmiştir.

\section{BULGULAR VE TARTIŞMA}

\section{Su Kullanım Randımanı}

Denmede uygulanan sulama suyu miktarı 293.7-489.5 mm arasında değişirken gerçek evapotranspirasyon (ETa) 320$582 \mathrm{~mm}$ arasında değişim göstermiştir. Artan sulama suyu uygulamasına bağı olarak bitki su tüketimleri de artış göstermiştir. Araştırmada belirlenen su kullanım randımanları, Çizelge 5'te verilmiştir. WUE'nn en yüksek ölçüldüğü T9FS125 uygulama konusunda $5.82 \mathrm{~kg} / \mathrm{da} / \mathrm{mm}$, en düşük olduğu uygulama T3KS75 konusunda 3.91 $\mathrm{kg} / \mathrm{da} / \mathrm{mm}$ olarak tespit edilmiştir. IWUE'nın ise en yüksek ölçüldüğü T9FS125 uygulama konusunda $6.92 \mathrm{~kg} / \mathrm{da} / \mathrm{mm}$, en düşük ölçüldüğü uygulama T3KS75 konusunda 4.26 $\mathrm{kg} / \mathrm{da} / \mathrm{mm}$ olarak elde edilmiştir. Sulama suyunun evapotranspirasyonu karşılama (I/ETc) oranında ise en yüksek \%94.1 ile T3FS125 konusu, en düşük ise \%80.5 ile T9KS75 konusunda olduğu tespit edilmiştir.

\section{Yeşil Ot Verimi}

Ortalama bitki yeşil ot verimleri $6087.78 \mathrm{~kg} / \mathrm{da}$ ile 11062.82 $\mathrm{kg} / \mathrm{da}$ arasında değişiklik göstermektedir. Konular arasındaki farklar \%5 önem seviyesinde istatistiksel olarak önemli bulunmuş ve yapılan t-testi karşılaştırmaları sonucunda oluşan gruplar Çizelge 6 'da sunulmuştur. Yapılan analiz sonucunda en yüksek ortalama yeşil ot verimi grup ortalaması bakımından T6KS75 konusunda $11062.82 \mathrm{~kg} / \mathrm{da}$ olarak elde edilirken, bunu 10918.72 ile T6TS100 konusu izlemektedir. En düşük ortalama yeşil ot verimi ise T9KS75 konusunda 6087.78 kg/da olarak saptanmıştır. Ergül (2008), Konya ili ekolojik koşullarında yaptığı çalışmada mısır yeşil ot verimini 6795 kg/da -10236 kg/da, Güçük ve Baytekin (1999), Şanlıurfa ili ekolojik koşullarında yaptıkları çalışmada yeşil ot verimini 9026 kg/da ile 9285 kg/da, Güneş (2004), Karaman ili ekolojik koşullarında yaptıkları çalışmada yeşil ot verimini $6892.80 \mathrm{~kg} / \mathrm{da}$ ile $8488.03 \mathrm{~kg} / \mathrm{da}$ olduğunu bildirmişlerdir. Söz konusu çalışmalardan biraz yüksek değerler elde edilmiştir. Buna neden olarak, sulama programında dinamik bir programın seçilmesi ve aynı zamanda da toprak organik madde fazlalığının buna katkı sağladığı düşünülmektedir.

\section{Bitki Boyu}

Yapılan gözlemlerde bitki boylarının $222.8 \mathrm{~cm}$ ile $283.0 \mathrm{~cm}$ arasında değişiklik gösterdiği belirlenmiştir. Uygulamaların bitki boyunda meydana getirdiği değişiklikler arasındaki farklar \%1 önem seviyesinde anlamlı bulunmuştur. Yapılan t

Çizelge 5. Su çalışmalarında dikkate alınan parametreler

\begin{tabular}{lccccc}
\hline Konular & $\begin{array}{c}\text { Uygulanan Sulama } \\
\text { Suyu Miktarları }(\mathbf{m m})\end{array}$ & $\begin{array}{c}\text { ETa } \\
(\mathbf{m m})\end{array}$ & $\begin{array}{c}\text { WUE } \\
\mathbf{( k g / d a / m m})\end{array}$ & $\begin{array}{c}\text { IWUE } \\
(\mathbf{k g} / \mathbf{d a} / \mathbf{m m})\end{array}$ & $\begin{array}{c}\text { I/ETc (\%) } \\
\text { T3KS75 }\end{array}$ \\
T3TS100 & 293.7 & 320 & 3.91 & 4.26 & 91.8 \\
T3FS125 & 391.6 & 419 & 4.62 & 5.94 & 93.5 \\
T6KS75 & 489.5 & 520 & 2.12 & 5.44 & 8.16 \\
T6TS100 & 293.7 & 350 & 3.59 & 4.27 & 84.0 \\
T6FS125 & 391.6 & 466 & 5.00 & 5.82 & 85.9 \\
T9KS75 & 489.5 & 570 & 4.82 & 6.00 & 80.5 \\
T9TS100 & 293.7 & 365 & 5.39 & 6.54 & 82.4 \\
T9FS125 & 391.6 & 475 & 5.82 & 6.92 & 84.1 \\
\hline
\end{tabular}

Çizelge 6. Konulara göre yeşil ot verimi, bitki boyu, bitki ağırlığı, yaprak sayısı ve yaprak ağırlığı parametrelerindeki değişim

\begin{tabular}{|c|c|c|c|c|c|}
\hline Uygulamalar & $\begin{array}{c}\text { Yeşil Ot Verimi } \\
\text { (kg/da) }\end{array}$ & $\begin{array}{l}\text { Bitki Boyu } \\
\text { (cm) }\end{array}$ & Bitki Ağırlığı (gr) & $\begin{array}{l}\text { Yaprak Sayısı } \\
\text { (adet) }\end{array}$ & Yaprak Ağırlığı (gr) \\
\hline T3KS75 & $7518.08^{\mathrm{cd}}$ & $239.2^{\text {bcd }}$ & $1021.11^{\mathrm{cd}}$ & $13.33^{a}$ & $183.40^{b c}$ \\
\hline T3TS100 & $8480.3^{b c}$ & $283^{a}$ & $1151.8^{b c}$ & $12.16^{a b c}$ & $196.13^{b}$ \\
\hline T3FS125 & $9563.22^{a b}$ & $274^{a}$ & $1298.88^{a b}$ & $11.33^{\mathrm{bcd}}$ & $207.9^{a b}$ \\
\hline T6KS75 & $11062.82^{a}$ & $252.6^{b}$ & $1502.56^{a}$ & $12.16^{\mathrm{abc}}$ & $256.18^{a}$ \\
\hline T6TS100 & $10918.72^{a}$ & $249.4^{b}$ & $1482.99^{a}$ & $12.16^{a b c}$ & $229.87^{a b}$ \\
\hline T6FS125 & $9797.68^{a b}$ & $247.2^{b c}$ & $1330.73^{a b}$ & $13.0^{a}$ & $209.56^{a b}$ \\
\hline T9KS75 & $6087.78^{d}$ & $222.8^{d}$ & $826.85^{d}$ & $11.0^{\mathrm{cd}}$ & $114.56^{d}$ \\
\hline T9TS100 & $7266.58^{c d}$ & $239.8^{b c d}$ & $986.95^{c d}$ & $10.33^{d}$ & $137.40^{c d}$ \\
\hline T9FS125 & $8409.62^{b c}$ & $230.8^{c d}$ & $1142.2^{b c}$ & $12.33^{a b}$ & $185.53^{b c}$ \\
\hline
\end{tabular}


testi karşılaştırma sonuçları Çizelge $6^{\prime}$ da sunulmuştur. En yüksek bitki boyu T3TS100 konusunda $283 \mathrm{~cm}$ olarak elde edilirken, bunu $274 \mathrm{~cm}$ ile T3FS125 konusu izlemektedir. En düşük bitki boyu ise T9KS75 konusunda $222.8 \mathrm{~cm}$ olarak ölçülmüştür. Bozkurt (2005), yaptığı araştırmada Çukurova koşullarında bitki boyunun 253-271 cm arasında değişiklik gösterdiğini, Gençel (2002), yaptığı çalışmada Harran ovasında bitki boylarının 242-289 cm arasında değişiklik gösterdiğini ve Gençoğlan (1996), Çukurova'da yaptı̆̆ı çalışmada farklı sulama suyu uygulamalarında bitki boylarının 168-246 cm arasında değişiklik gösterdiğini bildirmiş̧lerdir.

\section{Bitki Ağırlığı}

Yapılan gözlemler neticesinde ortalama bitki ağırlıkları 826.85 gr ile 1502.56 gr arasında değişiklik göstermiştir. Konular arasındaki fark istatistiksel olarak \%5 önem seviyesinde anlamlı bulunmuştur. Konulara ait ortalama değerlerin $t$ testi sonuçları Çizelge 6 'da verilmiştir. Yapılan test sonucunda en yüksek ortalama bitki ağırlığı T6KS75 konusunda 1502.56 gr olarak elde edilirken, bunu 1482.99 gr ile T6TS100 konusu izlemektedir. En düşük ortalama bitki ağırlığı ise T9KS75 konusunda 826.85 gr olarak saptanmıştır. Ergül (2008), Konya ekolojik koşullarında yaptıkları çalışmada bitki ağırlığını 851 gr ile 1444 gr arasında olduğunu bildirmiş ve elde ettiğimiz sonuçlarla benzerlik göstermektedir. Güneş (2004), Karaman ili ekolojik koşullarında yaptıkları çalışmada bitki ağırlığını $913.60 \mathrm{gr}$ ile 1198.00 gr arasında olduğunu, Sade ve ark. (2002), Konya ekolojik koşullarında yaptıkları çalışmada bitki ağırıı̆ını 715 gr ile 820 gr arasında olduğunu bildirmişlerdir. Çalışmadan elde edilen sonuçlar daha yüksektir. Bunun nedeni olarak bölge, çeşit, sulama programı ve toprak organik madde içeriğindeki farklıııklardan kaynaklandığı düşünülmektedir.

\section{Yaprak Sayısı}

Yaprak sayısı silajlık olan mısırlarda önemli bir unsurdur. Yaprak sayısının artmasıyla silajın kalitesi de artmaktadır (Orak ve İptaş, 1999, Sade ve ark., 2002; Güneş, 2004; Ergül, 2008). Yapılan ölçümlerde ortalama bitki yaprak sayıları 10.33 adet ile 13.33 adet arasında değişiklik göstermiştir.
Uygulamaların etkisi istatistiksel oBAK O, TAŞi Uygulamaların etkisi istatistiksel olarak \%1 önem seviyesinde anlamlı olarak belirlenmiştir. Konulara ait ortalama değerlerin $\mathrm{t}$ testi sonuçları Çizelge $6^{\prime}$ da verilmiştir. Yapılan test sonucunda en yüksek ortalama yaprak sayısı T3KS75 konusunda 13.33 adet olarak elde edilirken, bunu 13 adet ile T6FS125 konusu izlemektedir. En düşük yaprak sayısı ise T9TS100 konusunda ortalama 10.33 adet olarak saptanmıştır. Balmuk (2012), yaptığı çalışmada bitki yaprak sayılarının 12.33 ile 14.68 adet arasında değişiklik gösterdiği, Gürel (2007), yaptığı çalışmada bitki yaprak sayılarının 12.5 ile 15.3 adet arasında değişiklik gösterdiği, Kabakçı (2014), yaptıkları çalışmada bitki yaprak sayılarının 9.8 ile 14.6 adet arasında değişiklik gösterdiğini bildirmişlerdir. Çalışmadan elde edilen sonuçlarla benzerlik göstermektedir.

\section{Yaprak Ağırlığı}

Yapılan ölçümler neticesinde ortalama bitki yaprak ağırlıkları $114.56 \mathrm{gr}$ ile $256.18 \mathrm{gr}$ arasında değişiklik göstermiştir. Konular arasındaki farklar istatistiksel olarak \%1 önem seviyesinde anlamlı bulunmuştur. Konulara ait ortalama değerlerin t testi sonuçları Çizelge $6^{\prime}$ da verilmiştir. Yapılan test sonucunda en yüksek ortalama yaprak ağırı̆̆ı T6KS75 konusunda 256.18 gr olarak elde edilirken, bunu $229.87 \mathrm{gr}$ ile T6TS100 konusu izlemektedir. En düşük ortalama yaprak ağırlığı ise T9KS75 konusunda 114.56 gr olarak saptanmıştır. Moralar (2011), yaptığı çalışmada yaprak ağırlığını 60 gr ile 118.33 gr arasında bulmuştur. Çalışmadan elde edilen sonuçlardan düşüktür. Ancak, Ergül (2008), yaptığı çalışmada 126.33 gr ile 297.66 gr arasında, Sade ve ark., (2002), Konya ekolojik koşullarında yaptıkları çalışmada $247.5 \mathrm{gr}$ ile $323 \mathrm{gr}$ arasında bulmuşlardır ve çalışmayla benzerlik göstermektedir.

\section{Bitki Sap Çapı}

Yapılan gözlemler neticesinde ortalama bitki sap çapları $17.2 \mathrm{~mm}$ ile $27.3 \mathrm{~mm}$ arasında değişiklik göstermektedir. Konular arasındaki farklar istatistiksel olarak \%1 önem seviyesinde anlamlı bulunmuştur. Ortalama değerlerin $\mathrm{t}$ testi sonuçları Çizelge $7^{\prime}$ 'de verilmiştir. Yapılan test

Çizelge 7. Konulara göre bitki sap çapı, bitki sap ağırlığı, koçan yüksekliği ve koçan ağırlığı parametrelerindeki değişim

\begin{tabular}{lcccc}
\hline Uygulamalar & $\begin{array}{c}\text { Bitki Sap Çapı } \\
(\mathbf{m m})\end{array}$ & $\begin{array}{c}\text { Bitki Sap Ağırlığı } \\
\text { (gr) }\end{array}$ & Koçan Yüksekliği (cm) & Koçan Ağırlı̆̆ı (gr) \\
\hline T3KS75 & $21.2^{\mathrm{bc}}$ & $445^{\mathrm{cd}}$ & $97.16^{\mathrm{ab}}$ & $396.04^{\mathrm{de}}$ \\
T3TS100 & $21.4^{\mathrm{bc}}$ & $515^{\mathrm{c}}$ & $98.16^{\mathrm{ab}}$ & $440.66^{\mathrm{bcd}}$ \\
T3FS125 & $25.2^{\mathrm{ab}}$ & $627^{\mathrm{a}}$ & $101.16^{\mathrm{a}}$ & $464.81^{\mathrm{bcd}}$ \\
T6KS75 & $24.9^{\mathrm{ab}}$ & $652^{\mathrm{a}}$ & $90.5^{\mathrm{ab}}$ & $594.71^{\mathrm{a}}$ \\
T6TS100 & $27.3^{\mathrm{a}}$ & $710^{\mathrm{a}}$ & $84.75^{\mathrm{abc}}$ & $509.78^{\mathrm{ab}}$ \\
T6FS125 & $25.5^{\mathrm{ab}}$ & $623^{\mathrm{ab}}$ & $87.5^{\mathrm{abc}}$ & $497.83^{\mathrm{bc}}$ \\
T9KS75 & $17.2^{\mathrm{c}}$ & $370^{\mathrm{d}}$ & $82.33^{\mathrm{bc}}$ & $342.28^{\mathrm{e}}$ \\
T9TS100 & $22.4^{\mathrm{b}}$ & $442^{\mathrm{cd}}$ & $71.66^{\mathrm{c}}$ & $407.88^{\mathrm{cde}}$ \\
T9FS125 & $22.6^{\mathrm{b}}$ & $518^{\mathrm{bc}}$ & $87.16^{\mathrm{abc}}$ & $438.33^{\mathrm{bcd}}$ \\
\hline
\end{tabular}


sonucunda en yüksek ortalama bitki sap çapı T6TS100 konusunda $2.73 \mathrm{~mm}$ olarak elde edilirken, bunu $2.55 \mathrm{~mm}$ ile T6FS125 konusu izlemektedir. En düşük ortalama bitki sap çapı ise T9KS75 konusunda $1.72 \mathrm{~mm}$ olarak saptanmıştır. Torun (1999), Samsun ekolojik koşullarında yaptığı çalışmada sap çapını $18 \mathrm{~mm}$ ile $23 \mathrm{~mm}$ arasında, Keskin (2001), Konya ekolojik koşullarında yaptığı çalışmada sap çapını $17.13 \mathrm{~mm}$ ile $21.06 \mathrm{~mm}$ arasında, Kuşaksız (2011), yaptığı çalışmada sap çapını $18.7 \mathrm{~mm}$ ile $27.3 \mathrm{~mm}$ arasında ölçmüşler ve yapılan çalışmayla benzerlik göstermektedir.

\section{Bitki Sap Ağırığı}

Yapılan gözlemler neticesinde ortalama bitki sap ağırlıkları 370 gr ile 710 gr arasında değişiklik göstermektedir. Konular arasındaki fark istatistiksel olarak \%5 önem seviyesinde anlamlı olarak bulunmuştur. Konu ortalama değerlerin $t$ testi sonuçları Çizelge 7'de verilmiştir. Yapılan test sonucunda en yüksek ortalama bitki sap ağırlığı T6TS100 konusunda 710 gr olarak elde edilirken, bunu 651.66 gr ile T6KS75 konusu izlemektedir. En düşük ortalama bitki sap ağırlığı ise T9KS75 konusunda 370 gr olarak saptanmıştır. Ergül (2008), yaptığı çalışmada sap ağırlıklarını 394.00 gr ile $699.33 \mathrm{gr}$ arasında bulmuş ve çalışmadan elde edilen sonuçlarla benzerlik göstermektedir. Moralar (2011), yaptığı çalışmada sap ağırlığını 181.66 gr ile 203.33 gr arasında bulmuş ve çalışma sonuçlarında daha düşüktür. Bu farklılığın sebebi olarak bölge, iklim, çeşit, sulama uygulamaları ve toprak koşullarından kaynaklandığı düşünülmektedir.

\section{ilk Koçan Yüksekliği}

Yapılan gözlemler neticesinde ortalama bitki ilk koçan yükseklikleri $71.66 \mathrm{~cm}$ ile $101.16 \mathrm{~cm}$ arasında değişiklik göstermektedir. Konular arasındaki fark istatistiksel olarak \%1 önem seviyesinde anlamlı bulunmuştur. Konulara ait ortalama değerlerin $\mathrm{t}$ testi sonuçları Çizelge 7'de verilmiştir. Yapılan test sonucunda en yüksek ortalama ilk koçan yüksekliği T3FS125 konusunda $101.16 \mathrm{~cm}$ olarak elde edilirken, bunu $98.16 \mathrm{~cm}$ ile T3TS100 konusu izlemektedir. En düşük ortalama ilk koçan yüksekliği ise T9TS100 konusunda $71.66 \mathrm{~cm}$ olarak saptanmıştır. Bengisu (1994), yaptığı çalışmada ilk koçan yüksekliğini $93.33 \mathrm{~cm}$ ile 120.83 $\mathrm{cm}$ arasında bulunduğunu bildirmişlerdir. Elde ettiğimiz sonuçlar ile benzerlik göstermektedir. Öner ve ark., (2011), yaptıkları çalışmada ilk koçan yüksekliğini $92 \mathrm{~cm}$ ile $135 \mathrm{~cm}$ arasında olduğunu Aydoğan (2010), yaptıkları çalışmada ilk koçan yüksekliğini $106.8 \mathrm{~cm}$ ile $123.6 \mathrm{~cm}$ arasında olduğunu bildirmişlerdir ve elde ettiğimiz sonuçlardan yüksektir. Bu farklılığın sebebi olarak bölge, iklim ve çeşit farklılığından kaynaklandığı düşünülmektedir.

\section{Koçan Ağırlığı}

Yapılan gözlemler neticesinde ortalama bitki koçan ağırlıkları $342.28 \mathrm{gr}$ ile $594.71 \mathrm{gr}$ arasında değişiklik göstermektedir. Konular arasındaki fark istatistiksel olarak
\%5 önem seviyesinde anlamlı bulunmuştur. Konulara ait ortalama değerlerin $\mathrm{t}$ testi sonuçları Çizelge 7'de verilmiştir. Yapılan test sonucunda en yüksek ortalama koçan ağırlığı T6KS75 konusunda 594.71 gr olarak elde edilirken, bunu $509.78 \mathrm{gr}$ ile T6TS100 konusu izlemektedir. En düşük ortalama koçan ağırlığı ise T9KS75 konusunda 342.28 gr olarak saptanmıştır. Olgun (2011), Konya ekolojik koşullarında yaptığı çalışmada koçan ağırlığını 359.1 gr ile 590.7 gr arasında olduğunu bildirmişlerdir ve elde ettiğimiz sonuçlarla benzerlik göstermektedir. Ergül (2008), Konya ekolojik koşullarında yaptıkları çalışmada koçan ağırlığını 282.33 gr ile 453.66 gr arasında olduğunu, Bengisu (1994), Harran ovası ekolojik koşullarında yaptıkları çalışmada koçan ağırlığını 207.67 gr ile 354.33 gr arasında olduğunu bildirmişlerdir ve elde ettiğimiz sonuçlardan düşüktür. Bu farklılığın sebebi olarak bölge, iklim, çeşit, sulama uygulamaları ve toprak koşullarından kaynaklandığı düşünülmektedir.

\section{SONUÇ}

Balıkesir ili Manyas ilçesi koşullarında II. ürün silajlık mısır üretiminde dinamik sulama programı uygulanması durumunda ve yeşil ot verimi dikkate alındığında, 6 günde bir yığışımlı ETc değerinin \%75'inin sulama suyu miktarı olarak verilmesi doğru bir uygulama olacaktır. Ayrıca, dinamik sulama programı için ETo hesaplamasında FAO Penman Monteith yönteminin kullanılması ve yöre için mısır ilişkin önerilen Kc katsayları ile düzeltilmesi de gerekmektedir.

\section{KAYNAKLAR}

Açıkgöz E (1995) Yem Bitkileri, Uludağ Üniversitesi Ziraat Fakültesi Yayınları. Bursa.

Allen RG, Pereira LS, Raes D., Smith M (1998) Crop evapotranspiration - Guidelines for computing crop water requirements - FAO Irrigation and drainage paper 56, FAO, Rome.

Anonim 2019. http://www.may.com.tr/urun/hido

Arıtürk ME (2008) İkinci Ürün Silajlık Mısırın Sulama Zamanının Planlanması ve Su-Verim-Kalite İlişkilerinin Belirlenmesi. Yüksek Lisans Tezi. Namık Kemal Üniversitesi, Fen Bilimleri Enstitüsü, Tekirdağ...

Aydoğan V (2010) Ordu ilinde yetiştirilen Bazı Yerel ve Melez Mısır Çeşitlerinin Silaj Kalitelerinin Belirlenmesi. Yüksek Lisans Tezi, Ordu Üniversitesi, Fen Bilimleri Enstitüsü, Ordu.

Balmuk Y (2012) Konya Yunak Koşullarında İkinci Ürün Olarak Yetiştirilebilecek Silajlık Mısır (Zea mays L.) Çeşitlerinin Verim ve Verim Özelliklerinin Belirlenmesi. Yüksek Lisans Tezi Gaziosmanpaşa Üniversitesi, Fen Bilimleri Enstitüsü, Tokat.

Bengisu AG (1994) Harran Ovası Sulu Koşullarında İkinci Ürün Olarak Yetiştirilen Mısırda Verim ve Tarımsal Karakterler Arası İlişkilerin Saptanması Üzerine Bir Araştırma. Yüksek Lisans Tezi, Harran Üniversitesi, Fen Bilimleri Enstitüsü, Şanlıurfa. 
Bozkurt Y (2005) Çukurova Koşullarında Damla Sulama Yöntemi İle Sulanan II. Ürün Mısır Bitkisinde Optimum Lateral Aralığının Belirlenmesi, Yüksek Lisans Tezi, Çukurova Üniversitesi Fen Bilimleri Enstitüsü, Adana.

Ergül Y (2008) Silajlık Mısır Çeşitlerinin Önemli Tarımsal ve Kalite Özelliklerinin Belirlenmesi. Doktora Tezi Selçuk Üniversitesi Fen Bilimleri Enstitüsü, Konya.

Gençel B (2002) GAP (Güneydoğu Anadolu Projesi) Bölgesinde Ikinci Ürün Mısır Bitkisinin Damla Yöntemiyle Sulanması. Yüksek Lisans Tezi, Çukorova Üniversitesi, Fen Bilimleri Enstitüsü, Adana.

Gençoğlan C (1996) Mısır Bitkisinin Su-Verim Illişkileri, Kök Dağılımı ile Bitki Su Stresi Indeksinin belirlenmesi ve Ceres-Maize Bitki Büyüme Modelinin Yöreye Uyumluluğunun İrdelenmesi. Doktora Tezi. Çukurova Üniversitesi, Fen Bilimleri Enstitüsü, Adana.

Güçük T, Baytekin H (1999) Bozova Sulu Koşullarında İkinci Ürün Olarak Yetiştirilen Silaj Mısır, Silaj Sorgum ve Sorgum-Sudan Otu Melez Çeşitlerinde Hasat Zamanının Verim Ve Bazı Silaj Özelliklerine Etkisi. GAP I. Tarım Kongresi, 26-28 Mayıs 1999, s: 683-690 Şanlıurfa.

Güneş A (2004) Karaman Ekolojik Koşullarında Silajlık Hibrit Mısır Çeşitleri ve Sorgum-Sudan Otu Melezlerinin İkinci Ürün Olarak Yetiştirme Imkânlarının Belirlenmesi. Yüksek Lisans Tezi. Selçuk Üniversitesi, Fen Bilimleri Enstitüsü, Konya.

Gürel F (2007) Kastamonu Ekolojik Şartlarına Uygun Silajlık Mısır (Zea mays L.) Çeşitlerinin Belirlenmesi. Yüksek Lisans Tezi, Gaziosmanpaşa Üniversitesi Fen Bilimleri Enstitüsü, Tokat.

Howell TA, Cuenca RH, Solomon KH, (1990) Crop Yield Response Management of Farm İrigation Systems. Trans. ASAE Monograph Chap S. USA.

İptaş S., Avcıoğlu R., 1997. Mısır, sorgum, sudanotu ve sorgum sudanotu melezi bitkilerinde farklı hasat devrelerinin silo yemi niteliğine etkileri, Türkiye Birinci Silaj Kongresi Bildiri Kitabı, Hasad Yayıncılık, 42-51.

Kabakçı S (2014). Iğdır Ekolojik Şartlarına Uygun Silajlık Mısır Çeşitlerinin Belirlenmesi. Yüksek Lisans Tezi, Iğdır Üniversitesi Fen Bilimleri Enstitüsü, Iğdır.

Kanber R, Yazar A, Köksal H, Oguzer V (1992) Evapotranspiration of Grapefruit in The Eastern Mediterranean Region of Turkey. Scientia horticulturae, 52(1-2), 53-62.
KOBAK Ö, TAŞ i

Keskin S (2001) Silajlık olarak yetiştirilen mısır çeşitlerinde bitki sıklığının verim ve bazı kompenentlere etkisi. Yüksek Lisans Tezi Selçuk Üniversitesi Fen Bilimleri Enstitüs, Konya.

Kırtok Y (1998) Mısır Üretimi ve Kullanımı. Kocapluk Basım ve Yayınevi, İstanbul,

Kuşaksız T (2011) Manisa Ekolojik Koşullarında Ana Ürün Silajlık Olarak Uygun Mısır Çeşitlerinin Belirlenmesi. Türkiye 9. Tarla Bitkileri Kongresi s:529-532, Bursa.

Moralar E (2011) Tekirdağ İlinde Yetiştirilen Bazı Silajıł Mısır Çeşitlerinde Gelişme Sürecinin Belirlenmesi ve Verimliliklerinin Tespiti. Yüksek Lisans Tezi, Namık Kemal Üniversitesi, Fen Bilimleri Enstitüsü, Tekirdağ.

Olgun F (2011) Silajlık Melez Mısır Çeşitlerinin Farklı Hasat Zamanının Verimi, Verim Unsurları ve Kalite Üzerine Etkisi. Doktora Tezi Selçuk Üniversitesi Fen Bilimleri Enstitüsü, Konya.

Orak A, İptaş S (1999) Silo Yem Bitkileri ve Silaj, Çayır Mera Amenajmanı ve Islahı, Tarım ve Köyişleri Bakanlığı Tarımsal Üretim ve Geliştirme Genel Müdürlüğü, Ankara 49-69.

Öner F, Aydın I, Sezer I, Gülümser A, Özata E, Algan D (2011) Bazı Silajık Mısır Çeşitlerinde Verim ve Kalite Özelliklerinin Belirlenmesi. Türkiye 9. Tarla Bitkileri Kongresi, s:465-468, Bursa.

Sade B, Akbudak MA, Acar R, Arat E (2002) Konya Ekolojik Şartlarında Silajlık Olarak Uygun Mısır Çeşitlerinin Belirlenmesi. Hayvancılık Araştırma Dergisi 12 (1): 1722. Konya.

Sağlamtimur T, Tansı V, Baytekin H (1998) Yem Bitkileri Yetiştirme, Çukurova Üniversitesi Ziraat Fakültesi Ders Kitabı, Adana, No, 77.

Tanner OB, Sinclair TR (1983) Efficient Water Use in Crop Prodution; Research Limitation to Efficient Water Use in Crop Production. Ed. By HM.

Torun M, (1999). Samsun Şartlarında Silaj İçin Uygun Mısır Çeşitlerinin Belirlenmesi. Ondokuz Mayıs Üniversitesi Ziraat Fakültesi Dergisi, 14(1), 19-30.

Yasak S, Çınar A, Tugay ME (2003) Mısırda (Zea mays L,) Ekim Zamanının Tohum Tutma ve Diğer Bazı Özellikler Üzerine Etkileri. Türkiye 5. Tarla Bitkileri Kongresi, 1317 Ekim, Diyarbakır, 352-357.

Yolcu H, Tan M (2008) Ülkemizde Yem Bitkileri Tarımına Genel Bir Bakış. Tarım Bilimleri Dergisi, 14(3):303-312. 
